\title{
Correction to: Population cycles and outbreaks of small rodents: ten essential questions we still need to solve
}

\author{
Harry P. Andreassen ${ }^{1} \cdot$ Janne Sundell ${ }^{2} \cdot$ Fraucke Ecke $^{4} \cdot$ Stefan Halle $^{5} \cdot$ Marko Haapakoski $^{3} \cdot$ Heikki Henttonen $^{6}$. \\ Otso Huitu ${ }^{6}$. Jens $\mathrm{Jacob}^{7} \cdot \mathrm{Kaja}^{\mathrm{J}} \mathrm{J} \mathrm{hnsen}{ }^{1} \cdot$ Esa Koskela $^{8}$. Juan Jose Luque-Larena ${ }^{9}$. Nicolas Lecomte ${ }^{10}$. \\ Herwig Leirs ${ }^{11}$ • Joachim Mariën ${ }^{11}$. Magne Neby ${ }^{1}$. Osmo Rätti ${ }^{12}$. Thorbjörn Sievert ${ }^{3}$. Grant R. Singleton ${ }^{13,14}$. \\ Joannes van Cann ${ }^{8} \cdot$ Bram Vanden Broecke $^{11} \cdot$ Hannu Ylönen ${ }^{3}$ (D)
}

Published online: 30 January 2021

(c) The Author(s) 2021

\section{Correction to: Oecologia https://doi.org/10.1007/s00442-020-04810-w}

Authors would like to correct error in affiliation in the original publication of the article. Correct affiliation of Thorbjörn Sievert is updated here.

Correct affiliation of Thorbjörn Sievert to (3) not (2).

Open Access This article is licensed under a Creative Commons Attribution 4.0 International License, which permits use, sharing, adaptation, distribution and reproduction in any medium or format, as long as you give appropriate credit to the original author(s) and the source, provide a link to the Creative Commons licence, and indicate if changes

The original article can be found online at https://doi.org/10.1007/ s00442-020-04810-w.

Hannu Ylönen

hannu.j.ylonen@jyu.fi

1 Faculty of Applied Ecology, Agricultural Sciences and Biotechnology, Inland Norway University of Applied Sciences, Campus Evenstad, 2480 Koppang, Norway

2 Lammi Biological Station, University of Helsinki, Pääjärventie 320, 16900 Lammi, Finland

3 Department of Biological and Environmental Science, Konnevesi Research Station, University of Jyväskylä, P.O. Box 35, 40014 Jyväskylä, Finland

4 Department of Wildlife, Fish, and Environmental Studies, Swedish University of Agricultural Sciences, Skogsmarksgränd, 90183 Umeå, Sweden

5 Institute of Ecology and Evolution, Friedrich Schiller University Jena, Dornburger Str. 159, 07743 Jena, Germany

6 Terrestrial Population Dynamics, Natural Resources Institute Finland, Latokartanonkaari 9, 00790 Helsinki, Finland

7 Federal Research Centre for Cultivated Plants, Vertebrate Research, Julius Kühn-Institut, Toppheideweg 88, 48161 Münster, Germany were made. The images or other third party material in this article are included in the article's Creative Commons licence, unless indicated otherwise in a credit line to the material. If material is not included in the article's Creative Commons licence and your intended use is not permitted by statutory regulation or exceeds the permitted use, you will need to obtain permission directly from the copyright holder. To view a copy of this licence, visit http://creativecommons.org/licenses/by/4.0/.

8 Department of Biological and Environmental Science, University of Jyväskylä, P.O. Box 35, 40014 Jyväskylä, Finland

9 Departamento de Ciencias Agroforestales, Escuela Tecnica Superior de Ingenierias Agrarias, Universidad de Valladolid, Campus La Yutera, Avenida de Madrid 44, 34004 Palencia, Spain

10 Canada Research Chair in Polar and Boreal Ecology and Centre D'Études Nordiques, Department of Biology, Université de Moncton, 18 Avenue Antonine-Maillet, Moncton, NB E1A 3E9, Canada

11 Evolutionary Ecology Group, Department of Biology, University of Antwerp, Universiteitslain 1, 2610 Wilrijk, Belgium

12 Arctic Centre, University of Lapland, P.O. Box 122, 96101 Rovaniemi, Finland

13 International Rice Research Institute, DAPO Box 7777, Metro Manila, Philippines

14 Natural Resources Institute, University of Greenwich, Chatham Marine, Kent ME4 4TB, UK 